dental treatment and the need for antibiotic cover (usually by injection) may possibly have deterred some patients from having regular dental care. If prophylaxis is to have any impact on the incidence of endocarditis we suggest that the following measures should be adopted:

(a) simple written advice to patients, given on a standard card or letter as well as verbally, emphasising the importance of regular dental care as well as antibiotic cover;

(b) recording of this advice in hospital notes and in a letter to the family doctor to encourage reinforcement, as in $(c)$;

(c) regular reinforcement of this advice at each visit to the clinic;

(d) revision of advice on prophylaxis when appropriate in the light of new information;

(e) dental inspection by the clinic or family doctor to identify patients at particular risk who require direct referral for dental attention; and

$(f)$ direct communication with the patient's dental surgeon.

We thank Drs J V Jones, S C Jordan, and J R Rees for allowing us to study patients under their care and Dr Rees also for his help in preparing the manuscript.

1 Bayliss R, Clarke C, Oakley CH, Somerville W, Whitfield AGW, Young SEJ. The microbiology and pathogenesis of infective endocarditis. Br Heart 7 1983;50:513-9.

2 Bayliss R, Clarke C, Oakley CH, Somerville W, Whitfield AGW. The teeth and infective endocarditis. Br Heart $\mathcal{F}$ 1983;50:506-12.

3 American Heart Association Committee. Prevention of infective endocarditis. Circulation 1977;56: 139-43A.

4 Holbrook WP, Willey RF, Shaw TRD. Dental health in patients susceptible to infective endocarditis. BrMed f 1981;283:371-2.

(Accepted 1 September 1986)

Department of Cardiology, Bristol Royal Infirmary, Bristol BS2 8HW

DAVID W PITCHER, MD, MRCP, senior registrar

MARK PAPOUCHADO, MA, MRCP, registrar

KEVIN S CHANNER, $M D$, MRCP, registrar

MICHAEL A JAMES, MB, MRCP, registrar

Correspondence to: Dr D W Pitcher, County Hospital, Hereford HR1 2ER.

\section{Prevention of menstrual migraine by percutaneous oestradiol}

Roughly $60 \%$ of women with migraine relate the periodicity of their headaches to their menstrual cycles, and about a quarter of these women have their headaches exclusively at the time of menstruation. ${ }^{2}$ The physiological withdrawal of oestrogen during the premenstrual phase of the cycle has been suggested to be the precipitating event leading to these menstrual attacks. ${ }^{3}$ We investigated the effect of treatment with percutaneous oestradiol on menstrual migraine attacks.

\section{Patients, methods, and results}

Twenty women with menstrual migraine and regular menstrual cycles were included in the study. Menstrual migraine was defined as an attack of common migraine occurring exclusively just before or during menstruation (not earlier than two days before menstruation and no later than the last day of the menses). To be eligible women had to have experienced menstrual migraine during each of the previous 12 cycles. Furthermore, these 12 cycles had to have been regular, not differing from each other in duration by more than two days.

The study was a double blind placebo controlled crossover trial during three consecutive cycles. Successive patients were randomly allocated to receive the drugs in the order either oestradiol, placebo, oestradiol or placebo, oestradiol, placebo (table). The oestradiol preparation consisted of $1.5 \mathrm{mg}$ oestradiol in $2.5 \mathrm{~g}$ gel. Placebo was undiscernible and consisted of only $2.5 \mathrm{~g}$ of gel. Treatment was started 48 hours before the earliest expected onset of migraine and was repeated every day for seven days each month. Women were instructed to apply the gel to a surface of skin of at least $400 \mathrm{~cm}^{2}$-for example, the arms, shoulders, and abdominal skin - and to leave it to dry for five minutes before covering the skin with clothing. The main criterion of outcome was the presence or absence of menstrual attacks. When attacks occurred women were asked to record their duration and severity (graded as moderate or severe) and to treat them with aspirin. Women were also asked to report any side effects, particularly menstrual disorders, breast soreness, or mood changes. Statistical analysis was with McNemar's test.

Of the 20 women who entered the trial, 18 (mean age 42.5 years (range $32-53$ )) completed it, but one cycle of oestradiol treatment was missed because of amenorrhoea. Thus we analysed 26 cycles in which oestradiol was applied and 27 cycles in which placebo was applied. Menstrual attacks occurred in eight of the 26 oestradiol cycles $(30 \cdot 8 \%)$ and in 26 of the placebo cycles $(96 \cdot 3 \%)$ (table). The difference in response to treatment was highly significant $\left(\chi^{2}=9 \cdot 1, p<0 \cdot 01\right.$ for the comparison between the first and second cycles; $\chi^{2}=12, \mathrm{p}<0.001$ for the comparison between the second and third cycles). One patient had migraine three days after stopping oestradiol treatment. Attacks that occurred during oestradiol treatment were considerably milder and shorter than those occurring during placebo treatment. All but one of the attacks during oestradiol treatment lasted less than 12 hours and were graded as moderate, whereas all attacks during placebo treatment lasted 24 hours or more and 24 of the 26 were graded as severe. Aspirin was taken in three attacks during oestradiol treatment and 22 during placebo treatment. No breast soreness or mood change was observed. Modifications in cycles were observed in two of the 27 placebo cycles (amenorrhoea) and in four of the 26 oestradiol cycles (amenorrhoea in two, shortened cycle in one, and lengthened cycle in one).

Occurrence (and duration in hours) of perimenstrual migraine attacks in 18 patients (nine given the drugs in the sequence oestradiol, placebo, oestradiol and nine in the sequence placebo, oestradiol, placebo)

\begin{tabular}{rllll}
\hline Case No & Oestradiol & Placebo & Oestradiol & Placebo \\
\hline 1 & Yes (24) & Yes (48) & No & \\
6 & Yes (3) & Yes (24) & Yes (4) & \\
8 & No & Yes (24) & Yes (3) & \\
9 & No & Yes (48) & No & \\
10 & No & Yes (24) & No & \\
16 & Yes (12) & Yes (24) & No & \\
17 & No & Yes (48) & No & \\
18 & Yes (4) & No & No & Yes (48) \\
19 & No & Yes (36) & No & Yes (24) \\
3 & & Yes (24) & No & Yes (24) \\
4 & & Yes (48) & Yes (5) & Yes (24) \\
7 & & Yes (48) & No & Yes (48) \\
11 & & Yes (48) $(24)$ & No & Yes (48) \\
12 & & Yes (36) & No & Yes (24) \\
13 & & Yes (36) & No & Yes (36) \\
14 & & Yes (24) & No & \\
15 & & & & \\
20 & & &
\end{tabular}

\section{Comment}

Treatment with percutaneous oestradiol had a considerable preventive effect on pure menstrual migraine in women with regular cycles, which supports the view that it is the physiological withdrawal of oestrogen that precipitates menstrual attacks. This efficacy contrasts with the poor beneficial effect of oral oestrogens. ${ }^{4}$ Furthermore, percutaneous treatment is easy and well tolerated, thus offering considerable advantages over oestrogen injections ${ }^{3}$ and implants. ${ }^{5}$

1 Epstein MT, Hockaday JM, Hockaday TD. Migraine and reproductive hormones throughout the menstrual cycle. Lancet 1978; ; $543-5$.

2 Edelson RN. Menstrual migraine and other hormonal aspects of migraine. Headache 1985;25: 376-9.

3 Somerville BW. Estrogen-withdrawal migraine. 1. Duration of exposure required and attempted prophylaxis by premenstrual estrogen administration. Neurology 1975;25:239-44.

4 Dennerstein L, Laby B, Burrows GD, Hyman GJ. Headache and sex hormone therapy. Headach 1978;18:146-53.

5 Magos A, Zilkha K, Studd J. Treatment of menstrual migraine by oestradiol implants. $\mathcal{F}$ Neurol Neurosurg Psychiatry 1983;46:1044-6.

(Accepted 23 September 1986)

Department of Reproductive Endocrinology, Hôpital Necker, 75730 Paris Cédex 15, France

B DE LIGNIÈRES, $\mathrm{MD}$, assistant

$M$ VINCENS, $M D$, assistant

P MAUVAIS-JARVIS, $M D$, professor

Clinique des Maladies du Système Nerveux, Hôpital de la Salpêtrière, 75651 Paris Cédex 13, France

J L MAS, MD, assistant

P J TOUBOUL, $M D$, assistant

$M$ G BOUSSER, MD, professor

Correspondence to: Dr Mas.

\section{Correction}

Optimising antiemesis in cancer chemotherapy: efficacy of continuous versus intermittent infusion of high dose metoclopramide in emesis induced by cisplatin

We regret that an error occurred in this paper by Pamela $S$ Warrington and others (22 November, $p$ 1334). The lefthand part of figure 2 should be labelled "Continuous infusion," and the righthand part should be labelled "Intermittent infusion." In addition, the legend to figure 2 should read "Mean (SD) plasma concentrations of metoclopramide..." 